\title{
SU-8 Based Waveguide for Optrodes ${ }^{\dagger}$
}

\author{
Sara Pimenta 1,2,* João F. Ribeiro ${ }^{1,2}$, Sandra B. Goncalves ${ }^{1}$, Marino J. Maciel ${ }^{1}$, Rosana A. Dias ${ }^{2}$, \\ João Gaspar ${ }^{2}$, Reinoud F. Wolffenbuttel ${ }^{3}$ and José H. Correia ${ }^{1}$ \\ 1 CMEMS-UMinho, University of Minho, 4800-058 Guimarães, Portugal; jribeiro@dei.uminho.pt (J.F.R.); \\ sgoncalves@dei.uminho.pt (S.B.G.); mmaciel@dei.uminho.pt (M.J.M.); \\ higino.correia@dei.uminho.pt (J.H.C.) \\ 2 International Iberian Nanotechnology Laboratory (INL), 4715-330 Braga, Portugal; \\ rosana.dias@inl.int (R.A.D.); joao.gaspar@inl.int (J.G.) \\ 3 Faculty of EEMCS, TUDelft, Mekelweg 4, 2628 CD Delft, The Netherlands; r.f.wolffenbuttel@tudelft.nl \\ * Correspondence: sara.pimenta@dei.uminho.pt; Tel.: +351-253-510-190 \\ + Presented at the Eurosensors 2018 Conference, Graz, Austria, 9-12 September 2018.
}

Published: 30 November 2018

\begin{abstract}
Neural probes can be equipped with light for optogenetics applications. Different approaches are used for delivering light to the tissue: an optical fiber coupled to the probe, a $\mu$ LED or a waveguide integrated on the probe. Small probe dimensions, adequate optical power for photostimulation and good tissue penetration for in-vivo experiments are critical requirements. Thus, integrating a waveguide is a promising solution. This work shows the design and simulation of a SU-8 based waveguide for integration in a neural probe. The waveguide contains 3 apertures, spaced by $0.5 \mathrm{~mm}$, which will allow the photostimulation of different brain regions simultaneously.
\end{abstract}

Keywords: neural probe; optogenetics; waveguide

\section{Introduction}

In neuroscience, the study of the function and behavior of the central nervous system is done using implantable electrodes [1]. Emerged from neuroscience, optogenetics uses opsins which are introduced in target neuron cells, to produce a biological effect on those cells when they are exposed to light, with high temporal and spatial accuracy [2,3]. For example, channelrhodopsin-2 (ChR2) is a cation channel opsin that is directly activated by blue light, promoting cells depolarization [2]. A threshold of $1 \mathrm{~mW} / \mathrm{mm}^{2}$ for optogenetic activation is used as a reference [4].

An optogenetic implantable neural probe (optrode) can deliver light to the tissue through a waveguide [5,6], which presents several advantages over the use of optical fibers and $\mu$ LEDs, such as: minimizes tissue damage during in-vivo experiments, ensures the optical power required for optogenetics activation and improves the control of the distance between stimulation and recording sites in the neural probe.

This work presents the design and simulation of a SU-8 based waveguide for integration on a neural probe with several recording sites. The waveguide is composed by SU-8 core and PMMA cladding and contains 3 apertures or light outputs, spaced by $0.5 \mathrm{~mm}$. Thus, the neural probe will allow the photostimulation of different brain regions simultaneously.

\section{Materials and Methods}

Figure 1 shows an overall schematic of the neural probe integrating the waveguide and several recording sites. Figure 2 shows the simulated waveguide on Zemax ${ }^{\circledR}$ software and Table 1 shows the parameters used to implement the waveguide. The core layer is SU-8 $(n=1.61$ at $450 \mathrm{~nm})$ and the cladding layer is PMMA $(n=1.50$ at $450 \mathrm{~nm})$. An Al layer $(n=0.62$ at $450 \mathrm{~nm})$ was placed at the bottom 
and the end of the waveguide, featuring the increase of the amount of light that exits the waveguide apertures.

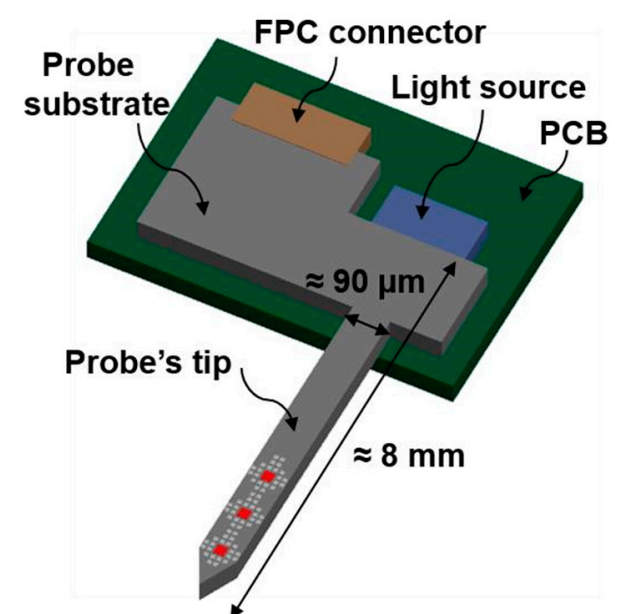

(a)

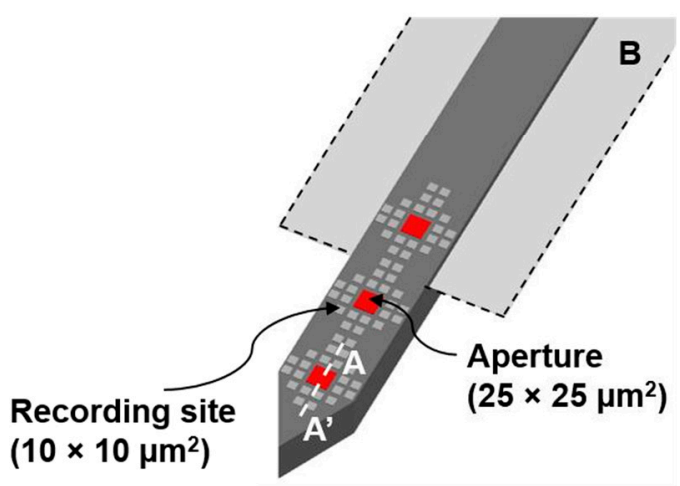

(b)

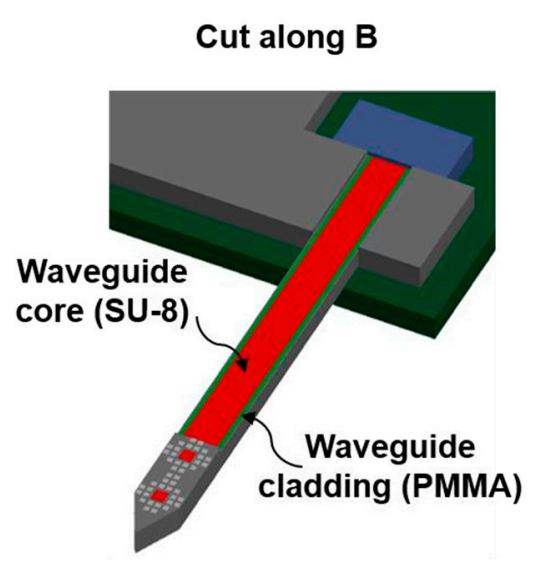

(c)

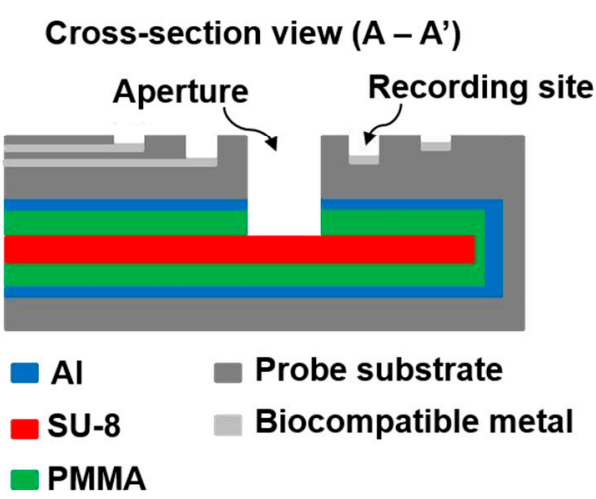

(d)

Figure 1. (a) Overall schematic of the final optrode; (b) Zoomed figure showing the probe's tip with several recording sites and 3 apertures or light outputs; (c) Cut along B (as indicated on (b)), showing the SU-8 based waveguide; (d) Cross-section view (A - $\left.\mathrm{A}^{\prime}\right)$, as indicated on (b).

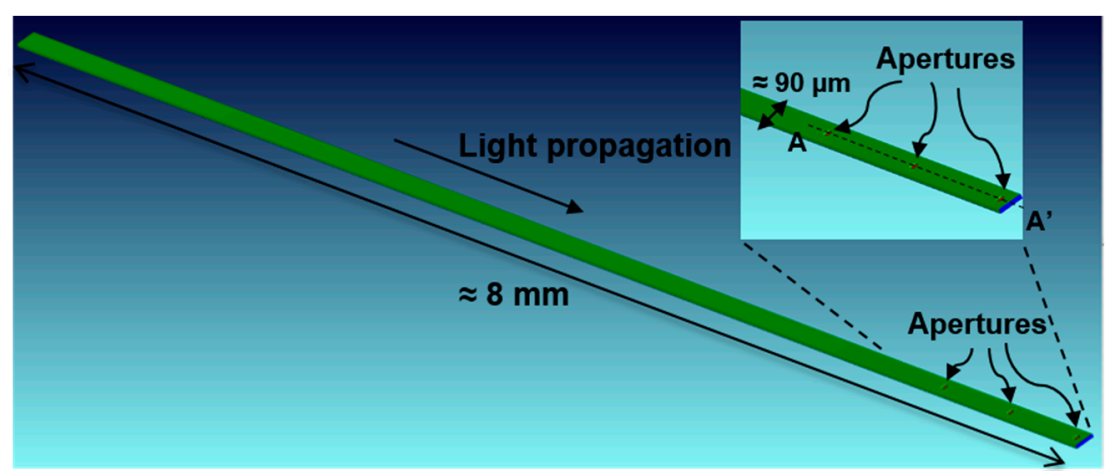

\section{Cross section view $\left(A-A^{\prime}\right)$}

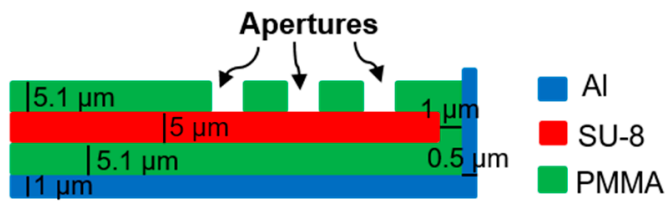

Figure 2. Geometry of the simulated waveguide. 
Table 1. Parameters used for implementation of the SU-8 based waveguide (Zemax ${ }^{\circledR}$ units - millimeters).

\begin{tabular}{lccccccc}
\hline Object Type & X Position & Y Position & Z Position & Material & $\begin{array}{c}\text { X1/X2 Half } \\
\text { Width }\end{array}$ & $\begin{array}{c}\text { Y1/Y2 Half } \\
\text { Width }\end{array}$ & Z Length \\
\hline Rectangular volume & 0 & 0 & 0.1 & Al & 0.0465 & 0.0005 & 8.0015 \\
Rectangular volume & 0 & 0.00305 & 0.1 & PMMA & 0.046 & 0.00255 & 8.001 \\
Rectangular volume & 0 & 0.00810 & 0.1 & SU-8 & 0.045 & 0.0025 & 8 \\
Rectangular volume & 0 & 0.01315 & 0.1 & PMMA & 0.045 & 0.00255 & 6.935 \\
Rectangular volume & 0 & 0.01315 & 7.06 & PMMA & 0.045 & 0.00255 & 0.475 \\
Rectangular Volume & 0 & 0.01315 & 7.56 & PMMA & 0.045 & 0.00255 & 0.475 \\
Rectangular Volume & 0 & 0.01315 & 8.06 & PMMA & 0.045 & 0.00255 & 0.04 \\
Rectangular Volume & -0.02875 & 0.01315 & 7.035 & PMMA & 0.01625 & 0.00255 & 0.025 \\
Rectangular volume & 0.02875 & 0.01315 & 7.035 & PMMA & 0.01625 & 0.00255 & 0.025 \\
Rectangular volume & -0.02875 & 0.01315 & 7.535 & PMMA & 0.01625 & 0.00255 & 0.025 \\
Rectangular volume & 0.02875 & 0.01315 & 7.535 & PMMA & 0.01625 & 0.00255 & 0.025 \\
Rectangular volume & -0.02875 & 0.01315 & 8.035 & PMMA & 0.01625 & 0.00255 & 0.025 \\
Rectangular volume & 0.02875 & 0.01315 & 8.035 & PMMA & 0.01625 & 0.00255 & 0.025 \\
Rectangular volume & 0 & 0.01065 & 8.1 & PMMA & 0.046 & 0.00505 & 0.001 \\
Rectangular volume & -0.0455 & 0.01065 & 0.1 & PMMA & 0.0005 & 0.00505 & 8 \\
Rectangular volume & 0.0455 & 0.01065 & 0.1 & PMMA & 0.0005 & 0.00505 & 8 \\
Rectangular volume & 0 & 0.0086 & 8.101 & Al & 0.0465 & 0.00810 & 0.0005 \\
\hline
\end{tabular}

For waveguide optical simulation on Zemax ${ }^{\circledR}$ software (at $450 \mathrm{~nm}$ ), a light source with $1.6 \mathrm{~W}$ total power and 3 detectors on the top of each aperture were used. Table 2 shows the parameters used for the light source and Table 3 the parameters used for the 3 detectors. Incoherent irradiance was analyzed for each detector.

Table 2. Parameters used for the light source (Zemax ${ }^{\circledR}$ units - millimeters).

\begin{tabular}{lccccccc}
\hline Object Type & X Position & Y Position & Z Position & Layout Rays & Analysis Rays & Power (W) & Cone Angle $\left(^{\circ}\right)$ \\
\hline Source point & 0 & 0.00810 & 0.1 & 1000 & 100,000 & 1.6 & 20 \\
\hline
\end{tabular}

Table 3. Parameters used for the 3 detectors (Zemax ${ }^{\circledR}$ units - millimeters).

\begin{tabular}{lccccccccc}
\hline Object Type & X Position & Y Position & Z Position & $\begin{array}{c}\text { Tilt about } \\
\text { X ( } \boldsymbol{(}^{\text {) }}\end{array}$ & Material & X Half Width & Y Half Width & X Pixels & Y Pixels \\
\hline Detector Rect & 0 & 0.016 & 7.0475 & 90 & Absorb & 0.013 & 0.013 & 100 & 100 \\
Detector Rect & 0 & 0.016 & 7.5475 & 90 & Absorb & 0.013 & 0.013 & 100 & 100 \\
Detector Rect & 0 & 0.016 & 8.0475 & 90 & Absorb & 0.013 & 0.013 & 100 & 100 \\
\hline
\end{tabular}

\section{Results and Discussion}

The mean total power and the mean peak irradiance (after three iterations) for each detector are presented on Table 4 . The obtained results meet the optogenetics requirements $\left(>1 \mathrm{~mW} / \mathrm{mm}^{2}\right)$. Important future guidelines include the validation of this design, by evaluating the experimental performance of the waveguide (after neural probe fabrication) and its coupling to the light source.

Table 4. Simulation results.

\begin{tabular}{cccc}
\hline Detector & Z Position $(\mathbf{m m})$ & Mean Total Power $(W)$ & Mean Peak Irradiance $\left(\mathbf{W} / \mathbf{m m}^{2}\right)$ \\
\hline 1 & 7.0475 & $3.27 \times 10^{-3}$ & $3.85 \times 10^{2}$ \\
2 & 7.5475 & $2.95 \times 10^{-3}$ & $3.19 \times 10^{2}$ \\
3 & 8.0475 & $2.65 \times 10^{-3}$ & $3.02 \times 10^{2}$ \\
\hline
\end{tabular}


Author Contributions: The work presented in this paper was a collaboration of all authors. J.F.R. conceived the neural probe design. S.P. and M.J.M. performed the modeling and simulations. S.P. and S.B.G. analyzed the results. R.A.D. and J.H.G. supplied design/fabrication considerations. R.F.W. contributed with resources. J.H.C. supervised all the work. S.P. wrote the article and all authors reviewed it.

Acknowledgments: ANI supports this work through the Brain-Lighting project by FEDER funds through Portugal 2020, COMPETE 2020 with the reference POCI-01-0247-FEDER-003416. S. B. Goncalves is supported by the Portuguese Foundation for Science and Technology, grant PD/BD/105931/2014, MIT-Portugal program.

Conflicts of Interest: The authors declare no conflict of interest.

\section{References}

1. Myllymaa, S.; Myllymaa, K.; Lappalainen, R. Flexible implantable thin film neural electrodes. In Recent Advances in Biomedical Engineering; Naik, G.R., Ed.; InTech: Vienna, Austria, 2009; pp. 165-190.

2. Goncalves, S.B.; Ribeiro, J.F.; Silva, A.F.; Costa, R.M.; Correia, J.H. Design and manufacturing challenges of optogenetic neural interfaces: A review. J. Neural Eng. 2017, 14, 041001, doi:10.1088/1741-2552/aa7004.

3. Gagnon-Turcotte, G.; Kisomi, A.A.; Ameli, R.; Camaro, C.O.; LeChasseur, Y.; Néron, J.L.; Bareil, P.B.; Fortier, P.; Bories, C.; de Koninck, Y.; et al. A Wireless Optogenetic Headstage with Multichannel Electrophysiological Recording Capability. Sensors 2015, 15, 22776-22797, doi:10.3390/s150922776.

4. Scharf, R.; Tsunematsu, T.; McAlinden, N.; Dawson, M.D.; Sakata, S.; Mathieson, K. Depth-specific optogenetic control in vivo with a scalable, high-density $\mu$ LED neural probe. Sci. Rep. 2016, 6, 28381, doi:10.1038/srep28381.

5. Wu, F.; Stark, E.; Im, M.; Cho, I.J.; Yoon, E.S.; Buzsáki, G.; Wise, K.D.; Yoon, E. An implantable neural probe with monolithically integrated dielectric waveguide and recording electrodes for optogenetics applications. J. Neural Eng. 2013, 10, 056012, doi:10.1088/17412560/10/5/056012.

6. Cho, I.-J.; Baac, H.W.; Yoon, E. A 16-site neural probe integrated with a waveguide for optical stimulation. In Proceedings of the IEEE 23rd International Conference on MEMS, Hong Kong, China, 24-28 January 2010; pp. 995-998, doi:10.1109/MEMSYS.2010.5442376.

(C) 2018 by the authors. Licensee MDPI, Basel, Switzerland. This article is an open access article distributed under the terms and conditions of the Creative Commons Attribution (CC BY) license (http://creativecommons.org/licenses/by/4.0/). 